\title{
$\underline{\text { Leisure as a cross-cultural concept }}$
}

By: Andrew Purrington and Benjamin Hickerson.

Purrington, A., \& Hickerson, B. (2013). Leisure as a cross-cultural concept. World Leisure Journal, 55(2), 125-137. doi: 10.1080/04419057.2013.782564

****) Taylor \& Francis. Reprinted with permission. No further reproduction is authorized without written permission from Taylor $\&$ Francis. This version of the document is not the version of record. Figures and/or pictures may be missing from this format of the document. $* * *$

This is an Author's Original Manuscript of an article published by Taylor \& Francis in World Leisure Journal on 04/30/2013 available online at http://www.tandfonline.com/10.1080/04419057.2013.782564.

\begin{abstract}
:
Leisure is a complex topic that, at times, appears to defy logical explanation. Research that examines and compares leisure cross-culturally can provide important information to aid our understanding of the phenomenon. With an increasing need for such studies, researchers have recognised that common academic definitions of leisure may not directly translate or be usefully applied in such research. In this paper, we re-examine the concept of leisure to develop an operational definition that is applicable across cultures and ensures comparability across study results. To do this, we review and incorporate theories and research from biology, anthropology, psychology, economics and leisure studies to identify key characteristics and develop a definition of leisure. We also discuss potential methodological and theoretical implications of using the proposed definition.
\end{abstract}

Keywords: leisure definition | leisure theory | measurement | leisure research | culture

\section{Article:}

\section{Introduction}

Leisure is a cross-culturally valid phenomenon that also appears to be a human universal (Brown, 1991; Chick, 1998). That is, all individuals, in all cultures or societies, ${ }^{1}$ experience what we would label as leisure, even though most languages do not contain a word that directly translates to the English term. ${ }^{2}$ Individuals everywhere possess free time that is not devoted to productive tasks. Activities, such as socialising, music, dancing and the recreational use of drugs or alcohol, are ubiquitous to human populations (Brown, 1991; Chick, 1998). Emotions typically associated with leisure experiences, such as pleasure, happiness, interest and joy, also appear to be panhuman (Brown, 1991; Chick, 1998). While leisure, as a category of behaviour or experience, is universal, participation in leisure clearly varies across populations and individuals. For example, while dancing is universal, the specific dances in which people participate vary across both cultural groups and time. Yet, leisure appears to vary in a systematic way and is not 
random. Games of strategy, for example, are more prevalent in socially complex or stratified societies than in egalitarian societies (Roberts, Arth, \& Bush, 1959).

The dual task of describing leisure and developing explanations that account for those descriptions has been the goal of researchers since the early days of the field of leisure studies. While most research on leisure has historically focused on Western populations, researchers are increasingly interested in the leisure behaviour and attitudes of individuals from non-Western cultural groups and societies (Allison, 1988; Chick, 2000; Valentine, Allison, \& Schneider, 1999). In order to gain a more complete understanding of leisure, cross-cultural research which highlights the similarities and differences among cultural groups is essential. An assessment of the cross-cultural similarities of leisure may provide insight for an ultimate, or evolutionary, explanation as to why leisure exists at all among humans. Understanding how leisure varies across cultures may suggest proximate explanations for what causes individuals to pursue, and cultural groups to maintain, specific leisure activities in a particular time and place.

While research on leisure in non-Western settings has become more common in recent decades (e.g., Cushman, Veal, \& Zuzanek, 2005), comparative, cross-cultural studies remain rare (Chick, 1999, 2000). ${ }^{3}$ Such cross-cultural research is difficult, if not impossible, without a clear, crossculturally valid conceptualisation of the leisure phenomenon. And despite leisure research in non-Western settings, most definitions of leisure contain value judgments or biases often unintentional which are indigenous to the European people of the USA and Western Europe. For example, the idea of "free will" underlies many understandings of leisure while many "generic" leisure activity lists are based on common North American of Western European leisure activities. The limited applicability and biases of most leisure definitions means they are not useful for conducting cross-cultural comparisons of leisure. It is not clear that the results obtained from such studies produce results that are comparable across cultural groups. Our goal in this paper is to develop a broadly applicable operational definition of leisure for the purpose of systematically examining the phenomenon cross-culturally.

Examining concepts Despite the apparent fact that people seem to intuitively understand what leisure is or are able to recognise it, efforts to produce a clear conceptualisation of leisure have been challenging. The most common conceptualisations define leisure as free time (Brightbill, 1960; May \& Petgen, 1960), as a specific set of activities (Dumazedier, 1960, 1974), as a state of mind (de Grazia, 1964) or experience (Neulinger, 1974). Other definitions have been proposed, but none are without limitations nor have they reached consensus. While multiple definitions may stimulate debate about leisure, having multiple definitions is, in many ways, tantamount to having no definition at all.

Well-defined concepts are fundamental to both theory and empirical research (Ember \& Ember, 2009; Goertz, 2005). Many definitions of leisure are developed using philosophic or semantic approaches that typically involve the historical use of a word or its meaning, often in a single language or culture. Even when such analyses involve a word's translation from one language into other languages, the goal is to better understand how people think about and use the term. Alternatively, a realist approach "involves a theoretical and empirical analysis of the object or phenomenon referred to by the word"' (Goertz, 2005, p. 4). It is not the word, but rather the phenomenon of interest that is the main focus. While a semantic approach can often provide 
insight into how a word has changed over time, one potential problem is that words can have multiple definitions, many of which may lack the clarity and precision necessary for research. This may be especially true of social science concepts when compared to concepts in the physical sciences that are not commonly used in everyday language (e.g., "quark"; " proton"; "endoplasm").

It is also important to distinguish between the perspective of the participants and the perspective of the research community, a distinction known as "emics" and "etics" (Harris, 2001). Emic descriptions and explanations are provided by participants, whereas etic descriptions and explanations are provided by researchers/the research community. ${ }^{4}$ According to Harris (2001, p. 32):

Emic operations have as their hallmark the elevation of the native informant to the status of ultimate judge of the adequacy of the observer's descriptions and analyses. The test of the adequacy of emic analyses is their ability to generate statements that the native accepts as real, meaningful, or appropriate. Etic operations have as their hallmark the elevation of observers to the status of ultimate judges of the categories and concepts used in description and analysis.

The goal of an emic description or analysis is to better understand how individuals who are embedded in a culture view a phenomenon, whereas the purpose of an etic description or analysis is to understand the phenomenon using concepts and techniques that are applicable across cultures or research settings. With respect to definitions, an emic perspective provides a folk definition while an etic perspective provides an operational definition that allows observers to measure the phenomenon. Of course, not just any observer from outside a culture can provide an etic description or analysis. Just as an emic description relies on informants who know the insider view of the system, an etic description depends on trained observers who are "familiar with certain canons of scholarly and scientific inquiry" and familiar with the phenomenon in other cultures (Harris, 1990a, p. 49). Of course, both emic and etic analyses can be undertaken subjectively or objectively depending on whether or not the methods employed meet the methodological standards required for scientific inquiry.

Both emic and etic perspectives are important to fully understand a phenomenon or concept. Neither the emic perspective nor the etic perspective is more "correct" or ontologically true than the other. Comparisons of emic descriptions across cultures provide insights into the similarities and differences in the ways individuals understand or think about a concept. Such analyses may show that certain concepts are universal or viewed similarly across a set of cultures. Etic analyses are important for describing a culture independently of its own ideas or concepts, and must employ concepts that are applicable across cultural settings. As a result, it is possible to identify similarities and differences in behaviour and thought independent of the views of individual participants. Behaviour does not always match the stated cultural norms or conventions, and some cultures lack concepts for behaviours. For example, not all cultures possess the concepts of "oxygen" or "orgasm," but the activities represented by these concepts will still be relevant to the behaviour of their members (de Waal, 2005, p. 96). In many ways, the distinction between emic and etic is heuristic, ${ }^{5}$ albeit a useful one that helps clarify the purposes 
of a study as well as the appropriate standards from which to judge its success or failure. The appropriate perspective for a given study depends on the purpose of that study.

To develop an empirically useful definition of leisure that is valid cross-culturally, we will employ a realist approach, focusing on the phenomenon of leisure referred to by researchers rather than on the semantic nature of the word. We also adopt an etic, or researcher oriented, perspective to develop an operational definition that can be applied across cultures and contexts by incorporating biological, cultural, economic and psychological theory with leisure research.

Characteristics of leisure In spite of disagreements over the definition of leisure, literature suggests that there are two important questions about the characteristics of leisure. First, what is the nature of leisure? In other words, is leisure behavioural (e.g., activity), psychological (e.g., experience) or something else (e.g., time)? Second, are leisure and work distinct and, if so, how should we demarcate them? While this feature of leisure has received considerable attention over the years, it is not always clear why this distinction is important or how best to define it.

\section{The nature of leisure}

Previous definitions have characterised leisure as a primarily temporal (e.g., free time), behavioural (e.g., activity) or mental (e.g., experience) phenomenon. Given these different perspectives on the fundamental nature of leisure, which provides a useful foundation for a definition of leisure? Time has long served as a basis for a definition of leisure (e.g., Brightbill, 1960; May \& Petgen, 1960). However, defining leisure as free time reduces leisure to the time remaining after work and necessities (i.e., it is residual). Furthermore, definitions of leisure based on time appear to be incomplete as descriptions of the amount of available leisure time are quickly disregarded in favour of descriptions of the behaviour or experiences associated with that time. Therefore, one of the major issues with defining leisure is whether leisure is defined behaviourally or psychologically.

Definitions of leisure as a psychological phenomenon have been popular in recent years, but they appear to be incomplete and logically inconsistent. If leisure is a behavioural phenomenon, associated mental states or experiences are causes, effects or both. On the other hand, if leisure " is only a mental state, then the nature of the stimulus is irrelevant" (Kelly, 1996, p. 21). Leisure could be a psychological phenomenon, such as "flow" (Csikszentmihalyi, 1975, 1990). However, as a purely experiential phenomenon, leisure could occur during work or other productive activities (e.g., Csikszentmihalyi, 1990). Leisure may be more likely to occur in certain settings, but is not tied to those settings. Many authors insist that leisure cannot occur during work (e.g., Iso-Ahola, 1999; Kelly, 1996), which suggests that experience, on its own, is not a sufficient definition of leisure.

Requiring leisure, as experience, to occur outside of work also suggests that the mental state of leisure is inseparable from behaviour. Only by considering individuals' behaviour and their mental state can we determine whether or not they are in leisure. As a result, leisure is a mental state that occurs during certain (leisure) activities. According to Mannell and Kleiber (1997), when "leisure is defined in terms of what people think and feel, researchers use measures that reflect mental experience while engaged in leisure activities"' (p. 55). But, leisure cannot 
simultaneously be "what people think and feel" and a type of activity. As both behaviour and experience, leisure is both cause and effect and, thus, circular.

We suggest that an amenable solution to those issues that intrude upon defining leisure is to use a behavioural approach. That is, leisure should refer to specific behaviours or actions and not thoughts or feelings. We are not advocating a return to a Skinnerian behaviourist programme that dismisses the importance of experience or the mind. Defining and describing leisure alone is not sufficient. We must also develop theories that explain our descriptions of leisure, which will undoubtedly require the examination of psychological factors. Individuals are guided by the information within their brains, while experiences are also important. Many proximate factors, including psychological dispositions and social and physical environments, influence leisure behaviour (Chick \& Dong, 2005; Richerson \& Boyd, 2005). Considering leisure as a behavioural phenomenon, what criteria can be applied cross-culturally that separate leisure behaviours from other behaviours?

\section{Demarcating work and leisure}

Almost unanimously, previous definitions of leisure raise the issue of a work-leisure distinction. Most free time and activity definitions explicitly distinguish work from leisure (e.g., Brightbill, 1960; Kelly, 1972), while experiential definitions (e.g., IsoAhola, 1999; Neulinger, 1974), more or less implicitly include this criterion. Our goal is to justify the importance of the distinction and suggest how the demarcation may be made.

Conceptually, the distinction between work and leisure reflects the fact that individuals must satisfy certain needs in order to survive. As living organisms, energy is fundamental to individuals' ability to do anything. In physiological terms, the energy from food can be allocated to four very general categories of use: maintenance, growth, reproduction and excretion (Sibly \& Calow, 1986; Ulijaszek, 1996; Wood, 1998). Maintenance includes the energy costs associated with the proper physiological functioning of the body, such as basal metabolism and the immune system, and tasks that immediately support these functions. Growth includes energy allocated to increase body mass or develop new tissue while reproduction includes the energy costs associated with producing offspring. Excretion, which accounts for approximately $35-40 \%$ of energy consumed, includes the energy lost through such things as heat production, digestion and waste removal. Thus, maintenance (and excretion) is an investment in individuals' current and impending survival while growth and reproduction are investments for the future.

Because energy is limited and the energy allocated to one category cannot be used in another, these four categories compete with one another. In biological terms, maintenance is fundamentally important. Energy must first be allocated to tasks that contribute to current survival and tasks that produce additional energy, such as the acquisition of food and water. Failure to do so makes future-oriented investments pointless. Energy available after maintenance tasks are accomplished and can then be spent on future-oriented investments. If leisure does not contribute to current survival, then it should be constrained by the available energy. Rubin, Flowers, and Gross (1986) demonstrated that the energy expended during leisure, but not work, decreases in response to negative changes in the ability of the local environment to produce an adequate diet. Similarly, play occurs only after individuals have adequate nutrition and are free 
of other stressors (Burghardt, 2005). Thus, while this topic remains largely understudied, evidence suggests that the energy invested in leisure is limited by available energy. In this respect, leisure is a future-oriented investment.

A definition of leisure which considers culture helps to clarify the relationship between leisure and economic activities that contribute to survival. ${ }^{6}$ Human behaviour is more diverse than the behaviour of other species, largely thanks to culture (Richerson \& Boyd, 2005). As a result, the behavioural tasks that contribute to survival in one society may be a form of leisure in another. Hunting, for example, is an economic activity for some while it is leisure for others. Thus, what constitutes economic and non-economic behaviour depends on cultural context. However, it is possible to think of both work and leisure as human universals (Brown, 1991; Chick, 1998; Murdock, 1945). That is, they are categories "of historically and behaviourally diverse elements which, nevertheless, have so much in common that competent observers feel compelled to classify them together'' (Murdock, 1960, p. 655). Hunting and gathering, subsistence agriculture, horticulture, pastoralism and modern industry are undertaken in order to acquire the basic means of survival (e.g., food, water and shelter) even if their relationship to survival is indirect, as in modern economies. For example, all humans need to acquire shelter regardless of whether that involves collecting the raw materials and constructing the domicile themselves or spending countless hours with realtors looking at houses or apartments.

Consideration of the importance of culture also prevents us being overly reductionist in our thinking of economic activities. We must also include the tasks and activities that, from an etic perspective, support the productive aspects of a society. 'Domestic', tasks, such as transporting fuel and water, processing food, cooking and caring for children, are equally important to the success or failure of an economic enterprise. At the same time, the population dynamics (i.e., demography) of a culture or society are important economic factors. The productive tasks of a society influence the dynamics of a population by exerting limits on the production of food and other necessary resources while the size and dynamics of a population may present its own influence on the productive opportunities of that society (Boserup, 1965, 1990; Harris, 2001; Malthus, 1798, 1830; Wood, 1998). Other factors, such as the political organisation, law enforcement, family structure and education practices of a society, are also important considerations in the larger economic picture. For example, as service- and information-based jobs become common in the USA, individuals increasingly require education systems that provide the knowledge and training needed for those jobs. Thus, the specific productive tasks we associate with "work" are tied into larger economic systems that exist as a means of meeting basic biological needs. From an etic perspective, leisure behaviours stand quite apart from this suite of activities.

\section{An initial definition of leisure}

Based on our assessment of the literature, we have identified two key characteristics of leisure. First, to keep the definition from becoming tautologous, we suggest leisure is best considered a behavioural phenomenon. Second, in accordance with previous leisure definitions and what is known about biology, we argue that leisure is separate from tasks related to survival. Therefore, leisure is behaviour that differs from culture-specific behaviours closely related to immediate survival and other practical necessities of life. At its core, this definition describes leisure as 
behaviour that occurs apart from the necessities of life, or in free time. In many ways, our proposed definition is similar to previous definitions of leisure as free time and as activity. It could even be viewed as a combination of these approaches. However, our definition does not presuppose value, causes or effects of leisure; it simply identifies the attributes of leisure. Furthermore, we have made moral issues irrelevant to the definition of leisure, such as identifying "true", or worthwhile aspects of leisure.

We intend that the proposed definition should be a place to begin the development of a crossculturally applicable operational definition of leisure. In developing a definition that is valid across cultural settings, we have attempted to identify characteristics of leisure that are universal, or at least appear to be so to an external observer, across cultures. In other words, we have attempted to define a category of behaviour rather define a specific behaviour, such as games (see Roberts et al., 1959). Given that the specific behaviours that are commonly classified under the rubric of "leisure" are so diverse and because of the lack of cross-cultural, descriptive information on leisure, our attempt at defining this class of behaviour is broad. We are optimistic, however, that an increase in cross-cultural knowledge about leisure will enable future researchers to refine the definition.

Of course, human behaviour is rarely clear-cut, and the definition we have proposed raises a few methodological issues. Individuals are often able to do more than one thing at the same time, sometimes blurring the line between leisure and economic behaviours. For example, individuals may socialise while working or listen to music while taking care of household chores. Similarly, it is important to remember that behaviour is continuous. There are no natural starts and stops in behaviour: ' an observer who claims to be recording 'natural breaks' in behaviour is merely relying on unstated operational rules' (Gross, 1984, p. 539). However, these are not, in-and-ofthemselves, substantive threats to measuring leisure. Researchers could focus on primary behaviour or record both, depending on the purpose of the study and the desired level of detail.

An additional issue is the degree to which behaviours directly contribute to economic tasks. If leisure behaviour affords participants some benefit apart from participation, then involvement in leisure could be considered as contributing, albeit distantly, to the economic enterprise of that society. For example, research by Roberts et al. (1959), Roberts and Barry (1976) and SuttonSmith and Roberts (1970) on game participation suggests that individuals learn and practice skills important for success in life (see also Bock, 2005; Bock \& Johnson, 2004). Similarly, how much time separates present- and future-oriented behaviours? Economic behaviours contribute to immediate survival while leisure behaviours do not. However, for many behaviours it is not entirely clear how much time separates a present-oriented (i.e., survival) benefit from a futureoriented benefit. For example, preindustrial farming requires farmers to till fields, plant seed, tend and harvest crops, even though they may not provide sustenance for several months. Meanwhile, modern post-industrial workers often have plenty of resources for survival in the immediate and near future, but failure to work would cause negative consequences within a few months for many of them. Furthermore, resting between bouts of work is common in subsistence agriculture but is such behaviour leisure or is it necessary because, without it, work in the field would not get done (e.g., Haswell, 1985)? Future research may be able to shed light on these issues, but it is conceivable that such distinctions will always remain arbitrary and depend on their usefulness for generating and testing hypotheses. 
Knowledge of the culture or society in question is necessary before we can identify its leisure repertoire. Understanding the sociocultural and economic environments of the research is essential to identifying leisure behaviours, which has implications for the methods used to study leisure (Bernard, 2011). Observational techniques may be especially useful in this respect as they have historically been used in anthropology and ethology for gaining an understanding of the research population. At the same time, surveys and interviews will continue to be important tools for understanding leisure. However, etic-oriented research requires that participants understand the etic definition of leisure (Bernard, 2011; Harris, 2001). Simply asking individuals what they did for leisure may be problematic as individuals are likely to respond with the activities they perceive to be leisure. Of course, less directed studies using surveys and interviews will remain an essential tool to ascertaining how individuals think of leisure as well as identifying inconsistencies between researcher and participant perspectives. Ultimately, the method chosen will depend on the theory and questions guiding the research.

\section{Implications}

A large proportion of people's lives are "concerned with the repeated experience of activities that have absolutely nothing to do with economic subsistence'" (Lewin, 1980, p. 9). Thus, in order to understand humans in all their complexity, we must understand leisure. Although research in the past few decades has greatly advanced our understanding of leisure, the picture is far from complete. A cross-culturally applicable definition of leisure is critical to advancing both the methods used to conduct research and the theories explaining leisure.

Failure to fully conceptualise and articulate a definition results in inconsistencies across studies that hinder the comparability or reliability of such research. As a result, it is potentially difficult to assess whether leisure patterns differ across cultures, or across time in a single culture, due to the use of different leisure definitions. Similarly, the use of multiple leisure definitions raises potential concerns for validity. For example, research using lists of common leisure activities often omit certain leisure activities, such as sex or drug use, providing an incomplete picture of leisure participation patterns.

The definition of leisure proposed in this article can aid theoretical treatments of leisure by defining leisure in a way that is applicable across cultures and contexts and providing clarity to the relationship between causes and effects. One of the primary advantages of the proposed definition is that it identifies leisure as the overarching domain for a broad array of related behaviours. In other words, leisure is a universal phenomenon among humans. As a result, researchers studying different cultures can potentially ensure that they are investigating the same phenomenon, which could provide insights into leisure (Allison, 1988; Chick, 1998). It is also possible for researchers to identify analogous behaviour, such as play, in other mammals for cross-species analyses of leisure, which are invaluable for understanding universal phenomena (Ember \& Ember, 2009).

While individuals typically do not think of dogs, cats, horses or non-human primates as enjoying leisure (but see Chick \& Barnett-Morris, 1987 for an exception), it is often recognised that these and many other species play (Burghardt, 2005). Yet, the terms appear to describe similar 
behaviour. Both play and leisure appear to be separate from the " practical necessities of life," occurring after individuals have adequate nutrition and are free of major stressors (Burghardt, 2005; Rubin et al., 1986). Leisure and play also appear to simulate or model culture- or speciesspecific survival activities (Bock, 2005; Bock \& Johnson, 2004; Burghardt, 2005; Roberts \& Sutton-Smith, 1962). For example, children play "house'" or other games that mimic domestic activities while adults play games that mimic real-estate investment or war. Examining the relationship between play and leisure may help advance leisure theory. For example, the development of self-discipline (Paus et al., 1999) and the acquisition of cultural norms (Richerson \& Boyd, 2005) that parallel the transition from "free" child play to "restrained" adult leisure may help shed light on the factors influencing the range of leisure behaviour.

Another advantage of the proposed definition is that it clearly separates leisure behaviour from associated mental states. This separation is necessary in order to develop useful theories of leisure. Defining leisure as behaviour would allow the identification of the mental " experience that results from recreation [leisure] engagements" (Driver \& Tocher, 1970, p. 10) as well as the factors causing that behaviour (e.g., attitudes, beliefs, culture and personality). As a result, it is necessary to investigate the cognitive conditions and experiences associated with leisure. For example, individuals may invest considerable time and energy in specific leisure behaviours (Stebbins, 1992, 1999). Understanding why individuals pursue such "serious leisure'” may provide insights into other aspects of leisure participation.

Understanding the role of perceived freedom and choice in individuals' decisions to pursue specific behaviours may provide insight into the proximate causes of leisure. Although an element of choice is included in many leisure definitions (e.g., Brightbill, 1960; Neulinger, 1974), the absence of physical or social obligations is rare and much of what individuals do is influenced by their social environment (Kelly, 1978; Richerson \& Boyd, 2005; Stebbins, 2005). The degree of volition is more appropriately, then, one of many constraints that "limit the formation of leisure preferences and ...inhibit or prohibit participation and enjoyment in leisure", (Jackson, 1991, p. 279). At the same time, understanding the socialisation and acculturation (Chick, 1991; Chick \& Barnett, 1995) processes whereby individuals adopt specific leisure behaviours and how culture potentially affects leisure-related cognition (e.g., D'Andrade, 1981), will help to explain leisure patterns and participation.

Energy allocation, as well as the general relationship between work and leisure, may provide insights into both the proximate factors influencing leisure participation and leisure's ultimate function. For example, Chick (2001) has suggested that adult human play may be a product of sexual selection, serving as a signal used in the selection of mates (see also Bliege Bird \& Smith, 2005; Chick, Yarnal, \& Purrington, 2012). If leisure is a future-oriented investment, then the function of leisure reasonably occurs in the future, and research should be directed at understanding how leisure influences future events. Of course, theory must be tested against empirical research. Our hope is that the ideas and definition presented here encourage and facilitate the cross-cultural research necessary to test these and other ideas.

\section{Conclusion}


Leisure remains an interesting and important concept that, nevertheless, continues to present definitional challenges. Yet, a clear definition is essential to our ability to understand leisure, especially as researchers increasingly recognise the need to examine leisure across cultures. While an ontologically "correct" or final definition is unlikely, it is possible to develop a working operational definition that is applicable and comparable across cultures. In this article, we have utilised theories and research from biology, anthropology, psychology and leisure studies to review the key characteristics of leisure and develop a cross-culturally functional definition. The definition presented in this article is intended as a starting point; additional work will be essential to fully address this task. Perhaps part of the difficulty of defining leisure is that, because of its ubiquity in our lives, we have so many preconceived ideas about it. Of course, that makes the need to define and understand leisure all the more interesting and important.

\section{Acknowledgements}

We are grateful to Garry Chick, Ondrej Mitas and James Wood as well as the editors and reviewers of the first draft of this paper for their thoughtful comments and helpful suggestions.

Notes

1. It is important to clearly define these terms, given their importance in this paper. Following the cognitive anthropology tradition, we define culture as the shared, socially transmitted and learned information (i.e., knowledge, beliefs, values and other things) in individuals' heads (see Chick, 2009; Goodenough, 1957; Roberts, 1964; Richerson \& Boyd, 2005). An individual culture, or cultural group, is a group of individuals with similar information, or " an 'information economy' in which information is received or created, retrieved, transmitted, utilized and even lost" (Roberts, 1964, p. 438), even though there is variation in the distribution of information within the group. Individuals with different leisure patterns, for example, behave differently because of differences in leisure-related cultural information. The term society is often reserved for larger, more complex groups, which may comprise several smaller cultural groups (e.g., "American society").

2. Informal research by Chick (1998) suggests that only about $10 \%$ of languages have a word that translates to the English term leisure, though it is often translated using a circumlocution that is frequently translated as free time. Many more languages possess a translation for recreation, and most languages (about $90 \%$ ) contain a term that translates as play.

3. While the edited volume by Cushman et al. (2005) includes research in non-Western locations, such as Hong Kong, Japan and Israel, most chapters are concerned with North American and European nations or nations heavily influenced by them (e.g., Australia and New Zealand). In fact, even the non-Western nations have strong historical ties with North America and Europe. Furthermore, such research is usually conducted at the national level. Research on smaller cultural groups is often limited to one facet of leisure (e.g., art, music, games and sports, free time); little research has been conducted on the full spectrum of leisure behaviour of nonWestern cultural groups. 
4. For the purposes of this paper we use the terms "emic" and "etic" in accordance with the work of Marvin Harris (1990a, 1990b, 2001), who developed the terms based on the early work of Kenneth Pike (1967). Our usage of the terms is common in anthropology and differs somewhat from their usage in other disciplines, such as cross-cultural psychology (e.g., Berry, 1969, 1990). In fact, individual researchers have defined and applied these terms differently. For a discussion of the different uses of these terms, see Headland, Pike, and Harris (1990).

5. In some ways, the research community is itself another sociocultural group with its own viewpoint making the etic, in some ways, a specific emic viewpoint (e.g., the "emic of the observer"). The difference is that the attempt is made by the research community to go beyond any single emic viewpoint, based on logical theory and empirical evidence. As such, the use of both terms is justifiable (Harris, 1990a, 1990b).

6. We use the term economic in a broadly anthropological sense to refer to a host of necessary tasks, such as procuring and preparing food and raising children. The term economic could be replaced with productive or utilitarian without much loss of meaning.

\section{References}

Allison, M. T. (1988). Breaking boundaries and barriers: Future directions in cross-cultural research. Leisure Sciences, 10(4), 247-259. doi:10.1080/01490408809512195

Bernard, H. R. (2011). Research methods in anthropology: Qualitative and quantitative (5th ed.). Lanham, MD: AltaMira.

Berry, J. W. (1969). On cross-cultural comparability. International Journal of Psychology, 4(2), 119-128. doi:10.1080/00207596908247261

Berry, J. W. (1990). Imposed etics, emics, and derived etics: Their conceptual and operational status in cross-cultural psychology. In T. M. Headland, K. L. Pike, \& M. Harris (Eds.), Emics and etics: The insider/outsider debate (pp. 84-99). Newbury Park, CA: Sage Publications.

Bliege Bird, R., \& Smith, E. A. (2005). Signaling theory, strategic interaction, and symbolic capital. Current Anthropology, 46(2), 221-248. doi:10.1086/427115

Bock, J. (2005). Farming, foraging, and children's play in the Okavango Delta, Botswana. In A. Pellegrini \& P. K. Smith (Eds.), The nature of play: Great apes and humans (pp. 254-281). New York, NY: Guilford.

Bock, J., \& Johnson, S. E. (2004). Subsistence ecology and play among the Okavango Delta peoples of Botswana. Human Nature, 15(1), 63-81. doi:10.1007/s12110-004-1004-x

Boserup, E. (1965). The conditions for agricultural growth: The economics of agrarian change under population pressure. Chicago: Aldine. 
Boserup, E. (1990). Economic and demographic relationships in development. Baltimore, MD: Johns Hopkins University Press.

Brightbill, C. (1960). The challenge of leisure. Englewood Cliffs, NJ: Prentice-Hall.

Brown, D. (1991). Human universals. Boston, MA: McGraw Hill. Burghardt, G. M. (2005). The genesis of animal play: Testing the limits. Cambridge, MA: MIT Press.

Burghardt, G. M. (2005). The genesis of animal play: Testing the limits. Cambridge, MA: MIT Press.

Chick, G. (1991). Acculturation and community recreation in rural Mexico. Play and Culture, 4, 185-193.

Chick, G. (1998). Leisure and culture: Issues for an anthropology of leisure. Leisure Sciences, 20(2), 111-133. doi:10.1080/01490409809512269

Chick, G. (1999). Leisure's anthropology and the anthropology of leisure: An examination of the coverage of leisure in anthropology texts and anthropology in leisure texts. Schole, 14, 19-35.

Chick, G. (2000). Editorial: Opportunities for cross-cultural comparative research on leisure. Leisure Sciences, 22(2), 79-91. doi:10.1080/014904000272867

Chick, G. (2001). What is play for? Sexual selection and the evolution of play. Play and Culture Studies, 3, 3-25.

Chick, G. (2009). Culture as a variable in the study of leisure. Leisure Sciences, 31(3), 305-310. doi:10.1080/01490400902837902

Chick, G., \& Barnett-Morris, L. (1987). The hairy leisure class: A consideration of leisure among nonhuman higher mammals. Presented at the Leisure Research Symposium, National Recreation and Park Association Congress for Recreation and Parks, New Orleans, LA.

Chick, G. E., \& Barnett, L. A. (1995). Children's play and adult leisure. In A. D. Pellegrini (Ed.), Play as multi-disciplinary inquiry: Essays in honor of Brian Sutton-Smith (pp. 45-69). New York, NY: Cambridge University Press.

Chick, G., \& Dong, E. (2005). Cultural constraints on leisure. In E. Jackson (Ed.), Constraints on leisure (pp. 169-183). State College, PA: Venture Publishing.

Chick, G., Yarnal, C., \& Purrington, A. (2012). Play and mate preference: Testing the signal theory of adult playfulness. American Journal of Play, 4, 405-438.

Csikszentmihalyi, M. (1975). Beyond boredom and anxiety: Experiencing flow in work and play. San Francisco, CA: Jossey-Bass. 
Csikszentmihalyi, M. (1990). Flow: The psychology of optimal experience. New York, NY: Harper and Row.

Cushman, G., Veal, A. J., \& Zuzanek, J. (Eds.). (2005). Free time and leisure participation: International perspectives. Cambridge, MA: CABI Publishing.

D'Andrade, R. G. (1981). The cultural part of cognition. Cognitive Science, 5(3), 179-195. doi:10.1207/s15516709cog0503_1

de Grazia, S. (1964). Of time, work, and leisure. Garden City, NY: Anchor Books.

de Waal, F. (2005). Our inner ape: A leading primatologist explains why we are who we are. New York, NY: Penguin.

Driver, B. L., \& Tocher, S. R. (1970). Toward a behavioral interpretation of recreational engagements, with implications for planning. In B. L. Driver (Ed.), Elements of outdoor recreation planning (pp. 9-31). Ann Arbor, MI: University Press.

Dumazedier, J. (1960). Current problems of the sociology of leisure. International Social Science Journal, 12, 522-531.

Dumazedier, J. (1974). Leisure and the social system. In J. F. Murphy (Ed.), Concepts of leisure (pp. 129-144). Englewood Cliffs, NJ: Prentice-Hall.

Ember, C. R., \& Ember, M. (2009). Cross-cultural research methods (2nd ed.). New York, NY: AltaMira.

Goertz, G. (2005). Social science concepts: A user's guide. Princeton, NJ: Princeton University Press.

Goodenough, W. H. (1957). Cultural anthropology and linguistics. In P. L. Garvin (Ed.), Report of the seventh annual round table meeting on linguistics and language study, monograph series on languages and linguistics, no. 9 (pp. 167-173). Washington, DC: Georgetown University Press.

Gross, D. R. (1984). Time allocation: A tool for the study of cultural behavior. Annual Review of Anthropology, 13(1), 519-558. doi:10.1146/annurev.an.13.100184.002511

Harris, M. (2001). Cultural materialism: The struggle for a science of culture (updated ed.). New York, NY: AltaMira.

Harris, M. (1990a). Emics and etics revisited. In T. M. Headland, K. L. Pike, \& M. Harris (Eds.), Emics and etics: The insider/outsider debate (pp. 48-61). Newbury Park, CA: Sage Publications.

Harris, M. (1990b). Harris's reply to Pike. In T. M. Headland, K. L. Pike, \& M. 
Harris (Eds.), Emics and etics: The insider/outsider debate (pp. 75-83). Newbury Park, CA: Sage Publications.

Haswell, M. R. (1985). Energy for subsistence (2nd ed.). London: Macmillan.

Headland, T. M., Pike, K. L., \& Harris, M. (Eds.). (1990). Emics and etics: The insider/outsider debate. Newbury Park, CA: Sage Publications.

Iso-Ahola, S. (1999). Motivational foundations of leisure. In E. L. Jackson \& T. L. Burton (Eds.), Leisure studies: Prospects for the twenty-first century (pp. 35-51). State College, PA: Venture Publishing.

Jackson, E. (1991). Leisure constraints/constrained leisure: Special issue introduction. Journal of Leisure Research, 23, 279-285.

Kelly, J. (1972). Work and leisure: A simplified paradigm. Journal of Leisure Research, 4, 5062. Kelly, J. R. (1978). Situational and social factors in leisure decisions. The Pacific Sociological Review, 21(3), 313-330. doi:10.2307/1388850

Kelly, J. (1996). Leisure. Boston: Allyn \& Bacon.

Lewin, R. (1980). An introduction to affluence. In J. Cherfas \& R. Lewin (Eds.), Not work alone: A cross-cultural view of activities superfluous to survival. Beverly Hills, CA: Sage Publications.

Malthus, T. R. (1798). An essay on the principle of population, as it affects the future improvement of society; with remarks on the speculations of Mr. Goodwin, M. Condorcet, and other writers. London: J. Johnson.

Malthus, T. R. (1830). A summary view of the principle of population. London: John Murray.

Mannell, R. C., \& Kleiber, D. A. (1997). A social psychology of leisure. State College, PA: Venture Publishing.

May, H., \& Petgen, D. (1960). Leisure and its uses. New York, NY: A.S. Barnes.

Murdock, G. P. (1945). The common denominator of cultures. In R. Linton (Ed.), The science of man in the world crisis (pp. 123-142). New York, NY: Columbia.

Murdock, G. P. (1960). Universal aspects of culture. In W. Goldschmidt (Ed.), Exploring the ways of mankind (pp. 653-662). New York, NY: Holt, Rinehart, and Winston.

Neulinger, J. (1974). The psychology of leisure. Springfield, IL: C.C. Thomas.

Paus, T., Zijdenbos, A., Worsley, K., Collins, D. L., Blumenthal, J., Giedd, J. N., ... Evans, A. C. (1999). Structural maturation of neural pathways in children and adolescents: In vivo study. Science, 283(5409), 1908-1911. doi:10.1126/science.283.5409.1908 
Pike, K. L. (1967). Language in relation to a unified theory of the structure of human behavior. The Hague: Mouton.

Richerson, P. J., \& Boyd, R. (2005). Not by genes alone: How culture transformed human evolution. Chicago, IL: University of Chicago Press.

Roberts, J. M. (1964). The self management of cultures. In W. H. Goodenough (Ed.), Explorations in cultural anthropology (pp. 433-454). New York, NY: McGraw-Hill.

Roberts, J. M., Arth, M. J., \& Bush, R. R. (1959). Games in culture. American Anthropologist, 61(4), 597-605. doi:10.1525/aa.1959.61.4.02a00050

Roberts, J. M., \& Barry III, H. (1976). Inculcated traits and game-type combinations: A crosscultural view. In T. T. Craig (Ed.), The humanistic and mental health aspects of sports, exercise and recreation (pp. 5-11). Chicago: American Medical Association.

Roberts, J. M., \& Sutton-Smith, B. (1962). Child training and game involvement. Ethnology, 1(2), 166-185. doi:10.2307/3772873

Rubin, J., Flowers, N. M., \& Gross, D. R. (1986). The adaptive dimensions of leisure. American Ethnologist, 13(3), 524-536. doi:10.1525/ae.1986.13.3.02a00080

Sibly, R. M., \& Calow, P. (1986). Physiological ecology of animals: An evolutionary approach. Palo Alto, CA: Blackwell Scientific. Stebbins, R. A. (1992). Amateurs, professionals, and serious leisure. Montreal, PQ: McGillQueen's University Press.

Stebbins, R. A. (1992). Amateurs, professionals, and serious leisure. Montreal, PQ: McGillQueen's University Press.

Stebbins, R. A. (1999). Serious leisure. In E. L. Jackson \& T. L. Burton (Eds.), Leisure studies: Prospects for the twenty-first century (pp. 69-79). State College, PA: Venture Publishing.

Stebbins, R. A. (2005). Choice and experiential definitions of leisure. Leisure Sciences, 27(4), 349-352. doi:10.1080/01490400590962470

Sutton-Smith, B., \& Roberts, J. M. (1970). The cross-cultural and psychological study of games. In G. Lu“schen (Ed.), The cross-cultural analysis of sport and games (pp. 100-108). Champaign, IL: Stipes.

Ulijaszek, S. J. (1996). Energetics, adaptation, and adaptability. American Journal of Human Biology, 8(2), 169-182. doi:10.1002/(SICI)1520-6300(1996)8:23.0. CO;2-Y

Valentine, K., Allison, M. T., \& Schneider, I. E. (1999). The one-way mirror of leisure research: A need for cross-national social scientific perspectives. Leisure Sciences, 21(3), 241-246.

doi:10.1080/014904099273129 
Wood, J. W. (1998). A theory of preindustrial population dynamics: Demography, economy, and well-being in Malthusian systems. Current Anthropology, 39(1), 99 135. doi:10.1086/ 204700 